Caligrama, Belo Horizonte, v.19, n.2, p. 61-82, 2014

\title{
O emprego de vírgula em construções causais e explicativas do português
}

\section{The use of the comma in causal and explanatory constructions in Portuguese}

Eliane Mourão

Universidade Federal de Ouro Preto (UFOP), Ouro Preto, Minas Gerais, Brasil. elianemourao15@gmail.com

Resumo: No quadro tradicional dos estudos da linguagem, a distinção entre orações coordenadas explicativas e subordinadas adverbiais causais determina o emprego de vírgula. Todavia, o quadro tradicional não fornece critérios que permitam diferenciar com o rigor necessário os dois tipos de oração. Trabalhamos com a hipótese de que isso se deve ao fato de esses critérios privilegiarem a estrutura sintática das orações, ignorando sua participação na organização textual. Desse modo, buscando compreender as condições de emprego dos sinais de pontuação com as construções do português brasileiro tradicionalmente denominadas coordenadas explicativas e subordinadas adverbiais causais, examinamos essas construções do ponto de vista do quadro da gramática funcional, em que fatores formais e textuais se associam na explicação dos fatos linguísticos. Valemo-nos principalmente de estudo realizado por Neves (1999) para estabelecermos as variáveis que deveriam compor nossa investigação. Examinamos qualitativa e quantitativamente dados das orações focalizadas extraídos das revistas Veja e Piauí. Distinguimos quatro padrões oracionais, aos quais se associa, como elemento caracterizador, o emprego de vírgula.

Palavras-chave: emprego de vírgula; orações explicativas; orações causais; fatores textuais. 
Abstract: In the traditional framework of language studies, the distinction between independent explanatory clauses and result clauses determines the use of comma. However, the traditional framework does not provide criteria which enable distinguishing these two types of clauses with adequate precision. We raise the hypothesis that this happens due to the fact that these criteria privilege the syntactic structure of the clauses, disregarding its participation in textual organization. Therefore, trying to comprehend the issues related to the use of punctuation marks in the Brazilian Portuguese structures traditionally called result clauses and independent explanatory clauses, we analyzed these clauses from the perspective provided by functional grammar, in which formal and textual factors are associated in the explanation of linguistic facts. We use, as a main source for our study, the research carried out by Neves (1999) to establish the variables that should be part of our investigation. We examine data from the analyzed clauses taken from the magazines Veja and Piaui qualitatively and quantitatively. We distinguish four clause patterns, with which is associated, as a characterizing element, the use of the comma.

Keywords: use of comma; independent explanatory clauses; result clauses; textual factors.

Recebido em 22 de setembro de 2014.

Aprovado em 03 de outubro de 2014.

\section{Introdução}

Este trabalho tem como objetivo apresentar os resultados de estudo sobre o emprego da vírgula com as construções do português brasileiro que a gramática tradicional denomina coordenadas sindéticas explicativas e subordinadas adverbiais causais. O problema que em princípio se coloca pode ser ilustrado pelas seguintes ocorrências:

(1) O País ganhou espaço no mercado mundial de commodities porque seu agronegócio é moderno, avançado tecnologicamente e competitivo. (Veja, 28 jul. 2010, p. 28, itálico nosso) 
(2) Stephanie recusa-se a perdoar quem a perseguia, porque não sente sinceridade nas tentativas de reaproximação. (Veja, 28 jul. 2010, p. 130, itálico nosso)

No exemplo (1), a oração introduzida pela conjunção porque (sublinhada) não é precedida de pontuação, caracterizando-se, de acordo com a gramática tradicional, como uma oração adverbial causal. No segundo exemplo, a estrutura (sublinhada) é aparentemente a mesma, mas a presença da vírgula seria um indicativo de que se trata, do ponto de vista da tradição, de uma oração coordenada sindética explicativa. O emprego da vírgula estaria, assim, associado a uma diferença gramatical. Para compreendê-lo, bastaria reconhecer que, em (1), a oração com porque está subordinada ao verbo da oração tradicionalmente denominada principal (o verbo ganhou em "o País ganhou espaço no mercado mundial de commodities") ${ }^{1}$, enquanto, em (2), diferentemente, a oração com porque não está subordinada a nenhum termo da oração que a precede, ela e a oração precedente estabeleceriam um vínculo exclusivamente semântico, relacionando-se como duas totalidades sintaticamente autônomas.

Todavia, assim como se pode dizer que a oração sublinhada no primeiro exemplo se subordina a ganhou, constituindo uma causa do processo expresso por esse verbo, pode-se dizer também que ela se vincula como um todo à oração que a precede, consistindo em uma explicação para o fato aí expresso. Essa dupla leitura é pertinente também para o exemplo (2). A questão é que, nesses casos, subordinação e coordenação, causa e explicação, não se distinguem com nitidez. Inclusive, em ambos os exemplos parece, à primeira vista, indiferente antepor ou não uma vírgula à oração com porque.

\section{A perspectiva tradicional: aprofundamentos}

O problema da distinção entre as orações coordenadas explicativas e as orações subordinadas adverbiais causais, que não se restringiria à ocorrência da conjunção porque ${ }^{2}$, não passa despercebido por todas

\footnotetext{
${ }^{1}$ Alguns estudiosos entendem que ganhou em ganhou espaço é um verbo suporte. Dessa perspectiva, a análise devia fazer referência ao conjunto ganhou espaço. Todavia, focaliza-se nesse momento o ponto de vista tradicional, para o qual não há verbo suporte. ${ }^{2}$ Cegalla (2002, p. 268-270), por exemplo, entende que, além de porque, que, porquanto e pois funcionam tanto como conjunções coordenativas explicativas quanto como
} 
as gramáticas tradicionais. Rocha Lima (1999, p. 275), por exemplo, reconhece que "nem sempre é fácil, por sem dúvida, diferençá-las com nitidez". Desse modo, ele busca elencar critérios de diferentes naturezas que possam auxiliar na identificação de um e outro tipo de oração. Quanto à coordenada explicativa, ele afirma o seguinte:

[...] é feita para introduzir uma idéia nova, dentro de uma sequência do tipo A + A. Por encerrar uma justificação do que se disse na oração anterior, tem, forçosamente, de seguir-se a essa. Por outro lado, separa-a da oração antecedente uma pausa de certa duração - pausa que, com frequência, se assinala por ponto-e-vírgula e, até, por ponto simples, além de se marcar, naturalmente, por vírgula:

"Não é oração aceitável a do ocioso; porque a ociosidade o dessagra." (ROCHA LIMA, 1999, p. 275)

O exame do exemplo fornecido pelo gramático ("Não é oração aceitável a do ocioso; porque a ociosidade o dessagra") é suficiente para se questionar a caracterização que ele propõe. $O$ fato de esse exemplo estar descontextualizado não permite avaliar se, de modo indubitável, a oração coordenada explicativa "é feita para introduzir uma idéia nova", se ela "tem, forçosamente, de seguir-se" à oração que estaria justificando e se ela é necessariamente precedida por "uma pausa de certa duração" (e, portanto, por um sinal de pontuação). Em relação à primeira característica, deve-se considerar que a novidade do conteúdo de um segmento linguístico não é um dado inerente a esse segmento, mas depende do texto e das circunstâncias em que ele é produzido. Quanto à colocação da oração explicativa, veja-se que, em princípio, não há nada que impeça uma troca de posição entre ela e a oração que a precede, de modo que a alternativa "Porque a ociosidade o dessagra, não é oração aceitável a do ocioso" mostra-se tão admissível quanto "Não é oração aceitável a do ocioso; porque a ociosidade o dessagra". De maneira equivalente, a presença de pausa não parece ser uma norma, visto que a supressão do ponto e vírgula presente no exemplo fornecido por Rocha Lima (1999) resulta em uma construção que, se considerada de uma perspectiva estritamente formal, é admissível: "Não é oração aceitável a do ocioso porque a ociosidade o dessagra".

conjunções adverbiais causais. Rocha Lima (1999, p. 275), por sua vez, refere-se apenas a que e porque como conjunções comuns aos dois tipos de oração. 
$\mathrm{Na}$ caracterização da oração subordinada adverbial causal, o gramático se refere novamente aos critérios da presença de pausa e da colocação, os quais, como se viu, não permitem, por si mesmos, diferenciar a oração coordenada explicativa. Pelos mesmos motivos, eles não são suficientes também para se identificar a subordinada adverbial causal. Em relação ao critério da novidade do conteúdo da oração, o gramático não volta a mencioná-lo, mas acrescenta que entre a oração subordinada adverbial causal e a oração a que ela se vincula (a principal) "existe, necessariamente, uma relação de 'causa' e 'conseqüência'" (Rocha Lima 1999, p. 275, itálico nosso). Essa necessidade não é, contudo, identificável no exemplo de oração subordinada adverbial causal que o próprio Rocha Lima (1999, p. 276) fornece: "O capitalista se matou porque estava arruinado". Trata-se aqui da suposta causa da deliberação de alguém (o capitalista), e não de uma causa necessária. Em outras palavras, o vínculo causal não é, no exemplo, um dado inquestionável da realidade, mas constitui o ponto de vista de quem o enuncia.

$\mathrm{O}$ quadro tradicional, representado neste trabalho por Rocha Lima (1999), mostra-se, pelos motivos expostos, insatisfatório na caracterização das orações coordenadas explicativas e das orações subordinadas adverbiais causais e, portanto, na definição das condições de uso da vírgula com essas orações. Algumas vezes, conforme se observou, o problema está não no critério em si, mas no modo como Rocha Lima (1999) o considera. Assim, a colocação e a novidade do conteúdo são, como se verá, aspectos realmente relevantes na compreensão das orações aqui focalizadas, mas exigem que se tomem essas orações como unidades integrantes de um domínio linguístico mais amplo - o texto.

\section{A perspectiva funcionalista: exigências pragmáticas}

Em estudo intitulado "As construções causais", realizado no âmbito do Projeto NURC (Norma Urbana Culta) e, portanto, referente ao português culto falado no Brasil, Neves (1999) contesta a distinção tradicional entre orações coordenadas explicativas e orações subordinadas adverbiais causais. $\mathrm{O}$ alvo de seu questionamento são os dois critérios de caracterização dessas orações considerados fundamentais pela tradição: 0 gramatical e o semântico, justamente aqueles que englobam os aspectos definidores da nomenclatura empregada pelo quadro tradicional. Em relação ao critério gramatical, que diz respeito às noções de coordenação e subordinação, Neves (1999) diz que 
Se o termo subordinação é excessivamente marcado do ponto de vista sintático para utilizar-se em referência a uma ligação entre "enunciados", ou "frases" (= atos de fala), o termo coordenação, por outro lado, precisa ser mais definido para se referir a esse tipo de ligação (no caso a tradicionalmente chamada "coordenação explicativa"). (NEVES, 1999, p. 475)

O problema do critério semântico estaria no fato de que, da perspectiva da enunciação, as noções de causa e de explicação fornecidas pelo quadro tradicional não diferenciam efetivamente segmentos linguísticos reais. Desse modo,

não é o pretenso refinamento da interpretação semântica (distinguindo entre "causa", "razão", "motivo", "explicação", "justificação", etc.) que vai, por si, responder pela distinção entre esses dois grandes grupos que a tradição vem contrastando sob os rótulos de "subordinadas causais" e "coordenadas explicativas". (NEVES, 1999, p. 475)

Neves (1999) desenvolve um estudo das construções causais cujos resultados abrangem, indiferentemente, orações coordenadas explicativas e subordinadas adverbiais. Outras características que não as implicadas nessas denominações, características baseadas em outro ponto de vista sobre a linguagem que não o tradicional, são examinadas por ela. Interessam aqui aquelas que Neves (1999) toma como pragmáticas, situando-as em uma parte de seu texto intitulada "Uma avaliação pragmática das construções causais". Trata-se precisamente de traços relativos ao caráter da informação, se dado ou novo, e à posição da oração, se anteposta ou posposta à oração-núcleo, ou seja, às características que Rocha Lima (1999) menciona, mas, agora, com tratamento e aprofundamento novos.

Neves (1999) propõe dois esquemas de compreensão das orações causais em que se conjugam a posição da oração e a novidade do seu conteúdo. Um deles corresponde ao emprego da conjunção como, que, em sua investigação, é a mais recorrente entre as conjunções que introduzem orações causais antepostas. Veja-se o dado de ocorrência de como examinado pela autora: 
Como eu gosto por exemplo muito de feijão... muito de arroz... que são coisas que engordam e pra eu manter isso na hora do almoço... eu não posso carregar demais na hora da/do café... (NEVES, 1999, p. 466) o seguinte:

O esquema de compreensão da informação, segundo Neves, seria

A: Eu gosto de feijão e arroz, que engordam, não é?

B: (É)

A: Então/por isso eu não posso carregar na hora do café. (NEVES, 1999, p. 466)

O emprego da oração causal introduzida por como corresponderia a um diálogo em que o conteúdo dessa oração é tomado como pressuposto, como ideia compartilhada por falante e ouvinte (A e B, respectivamente). Assim, B concorda com esse conteúdo: "É". A informação expressa pela oração causal funcionaria, assim, como base para o que se vai enunciar por meio da oração-núcleo; por sua vez, a oração-núcleo constituiria um rema, a informação nova do discurso, o conteúdo visado pelo enunciador.

O outro esquema estaria relacionado ao emprego da conjunção porque, a mais recorrente entre as conjunções que, na investigação de Neves (1999), introduzem as orações causais pospostas. O dado de emprego de porque examinado pela autora é o seguinte:

eu tenho ido pouco ao cinema porque éh:: sei lá eu:: o pessoal que vai "ah::" diz que tal filme não é bom eu prefiro ficar em casa e não ir mas tenho assistido filmes bons. (NEVES, 1999, p. 469)

Por sua vez, o esquema interpretativo correspondente a esse exemplo seria este:
A: Eu tenho ido pouco ao cinema.
B: (É? Por quê?)
C: Porque o pessoal que vai diz que o filme não é bom.
(NEVES, 1999, p. 469)

Haveria aqui uma inversão em relação ao esquema anterior, visto que a oração causal passaria a veicular a informação requerida, ou seja, a informação nova. A oração-núcleo operaria nesse caso como suporte, como o tema no qual a oração causal se apoiaria. Desse modo, o ouvinte 
não se contentaria com a ideia expressa na oração-núcleo. A pergunta de B no esquema - "Por quê?" - representa uma expectativa de avanço do conteúdo em relação ao tema a qual orientaria a construção do enunciado.

As construções causais com outras conjunções se conformam, segundo Neves (1999), a um desses esquemas, dependendo da posição que ocupam relativamente à oração-núcleo. Quanto à opção por organizar o enunciado em conformidade com os esquemas propostos, Neves (1999, p. 470-471) afirma que não é possível:

Limitar a investigação da ordem ao contexto formado pelas duas orações ligadas pelo nexo semântico causal, já que [...] o próprio aparecimento em primeiro lugar de uma ou outra dessas orações é determinado pela organização discursiva, especialmente por pressões de continuidade tópica.

Trata-se, segundo a estudiosa, de colocar sempre à direita a oração cuja informação é nova, segundo as exigências de desenvolvimento do discurso.

A “avaliação pragmática das construções causais" realizada por Neves (1999) orientou o estudo que aqui se relata. Na investigação do emprego da vírgula com as orações do português escrito brasileiro conhecidas na tradição como coordenadas explicativas e subordinadas adverbiais causais, estabeleceu-se um corpus constituído por três volumes da revista Piauí, de que se extraíram 62 dados dessas orações, e por cinco volumes da revista Veja, de que se extraíram 53 dados dessas orações. Relativamente restrito, o corpus foi selecionado em função de esses veículos de comunicação constituírem referência de escrita culta, permitindo que se opere em um universo mais estável de emprego da vírgula. Longe de se almejar um panorama completo desse emprego com as construções focalizadas, buscou-se assim discernir tendências que pudessem referenciar estudos posteriores mais amplos.

No levantamento de dados, excluíram-se as orações com verbos na forma nominal, ou seja, as chamadas orações reduzidas, considerandose apenas, sem o cuidado de diferenciá-las entre si, as orações introduzidas pelas conjunções denominadas, no âmbito dos estudos tradicionais, coordenativas explicativas e subordinativas adverbiais causais. Essas orações passam a ser chamadas neste trabalho oração 2, e aquelas às quais elas se vinculam passam a ser chamadas oração $1^{3}$,

${ }^{3}$ Algumas vezes o segmento linguístico denominado oração 1 não é, de fato, uma 
independentemente da natureza gramatical do vínculo (se subordinação ou coordenação). Quanto ao exame dos dados, levaram-se em conta as seguintes variáveis: emprego da vírgula ( $\operatorname{sim} /$ não); conjunção (com/ porqueljá que, entre outras); posição da oração 2 (anteposta/posposta à oração 1); informação dada (expressa pela oração 1/pela oração 2/por nenhuma das duas); continuidade tópica (baseada na oração $1 /$ na oração 2/em nenhuma das duas).

As duas últimas variáveis - continuidade tópica e informação $d a d a$ - dizem respeito à novidade da informação expressa pelas orações examinadas. A compreensão do que se pretendeu com elas depende de dois esclarecimentos. Em primeiro lugar, sobre a relação entre os segmentos linguísticos que se denominam tema e rema, de um lado, e aqueles que se denominam informação dada e informação nova, de outro. Diferentemente de Neves (1999), que os associa, tomando o tema como informação dada e o rema como informação nova, assume-se, em consonância com Halliday (2004), que eles não são necessariamente coincidentes:

Abaixo da oração complexa, a gramática administra o fluxo do discurso por meio de recursos estruturais; e aqui operam dois sistemas relacionados entre si. Um é o sistema da oração, do TEMA [...] O sistema do TEMA constrói a oração na forma de uma mensagem, como junção de Tema + Rema. O outro é o sistema de INFORMAÇÃO. Este não é um sistema da oração, mas de uma unidade gramatical separada, a unidade de informação [...] A unidade de informação é uma unidade paralela à oração e às outras unidades que pertencem à mesma escala ordenada da oração [...] (HALLIDAY, 2004, p. 88, tradução nossa)

Embora, segundo Halliday (2004), a estrutura temática e a estrutura de informação coincidam na situação não marcada (situação recorrente no texto escrito, que não poderia se valer da gama de recursos prosódicos da fala), a coincidência não é obrigatória - o tema é um segmento linguístico que se situa necessariamente no início da sentença, enquanto a informação dada pode se situar em outras posições ${ }^{4}$. Assim,

oração, mas um item anafórico ou um termo composto por um item anafórico a que se vincula uma oração introduzida por porque.

${ }^{4}$ Algumas vezes, as sentenças que integram os dados deste trabalho não são introduzidas nem por uma oração causal, nem por uma oração-núcleo, mas por um segmento 
examinaram-se as construções focalizadas neste trabalho exclusivamente do ponto de vista da informação, que é o que se pressupôs ser relevante para o emprego da vírgula, conforme sugerido pela própria literatura tradicional.

A outra observação diz respeito exclusivamente às noções de dado e novo, que não devem ser compreendidas de uma forma literal. Mais uma vez, adota-se a concepção de Halliday (2004):

Podemos agora ver mais claramente o que os termos Dado e Novo realmente significam. A variável significativa é: informação que é apresentada pelo falante como recuperável (Dada) ou não recuperável (Nova) para o ouvinte. O que é tratado como recuperável pode ser entendido assim porque foi mencionado antes; mas essa não é a única possibilidade. Pode ser algo que está na situação [...] ou no ar, por assim dizer; ou algo que não está em lugar nenhum, mas que o falante quer apresentar como Dado para fins retóricos. O sentido é: isso não é novo. (HALLIDAY, 2004, p. 91, tradução nossa)

Desse modo, qualificar uma informação como dada ou nova não é uma operação que depende apenas do fato de essa informação ter sido ou não efetivamente mencionada, de modo que uma investigação baseada na novidade da informação pode se tornar bastante complexa e imprecisa. Uma solução é restringir essa investigação à menção efetiva, sem pretender, portanto, estabelecer a novidade das unidades linguísticas examinadas em termos de frequência real, mas visando ao estabelecimento do seu potencial de novidade em termos de "sim" (existe potencial) e de "não" (não existe potencial). Se, por exemplo, em relação à informação expressa por um número de unidades de um conjunto específico se pode dizer que já foi efetivamente mencionada, então esse conjunto tem potencial para constituir informação dada. É ao estabelecimento desse potencial que se pretendeu com a variável informação dada.

Enquanto a variável informação dada constitui um modo de avaliar as construções examinadas olhando-se o passado do texto até

linguístico de outra natureza. Nesse caso, tal segmento é o tema da sentença, e as orações causal e núcleo só podem ser examinadas em relação à novidade da informação. 
a ocorrência de cada uma delas, a variável continuidade tópica constitui um modo de avaliar essas mesmas construções olhando-se o futuro do texto a partir da sua ocorrência. A intenção nesse último caso é verificar a partir de que oração, se da oração 1 ou da oração 2, desenvolve-se a informação subsequente. Só se pode fazer isso de modo seguro se a informação subsequente dá continuidade à informação veiculada por uma dessas orações, sem que se altere a continuidade tópica do texto. Trata-se, mais uma vez, de uma opção que conduz não à frequência verdadeira de orações que trazem uma contribuição para o desenvolvimento tópico do texto, mas à caracterização de um tipo de oração como capaz ou não de portar a informação nova.

Definidas, assim, as variáveis por meio das quais os dados levantados seriam examinados, obtidos os valores de variáveis relativos a cada um desses dados, procedeu-se a uma análise estatística, para a qual se empregou o programa eletrônico Minitab $16^{5}$.

\section{Os resultados: o emprego da vírgula segundo quatro padrões de construção}

As construções que constituem os dados deste estudo caracterizamse pela presença das conjunções como, já que, na medida em que, pois, porque e uma vez que, configurando uma variedade muito menos ampla do que a sugerida pela literatura tradicional. O quadro abaixo mostra a ocorrência dessas conjunções:

Tabela 1 - Ocorrência de conjunções conforme o veículo

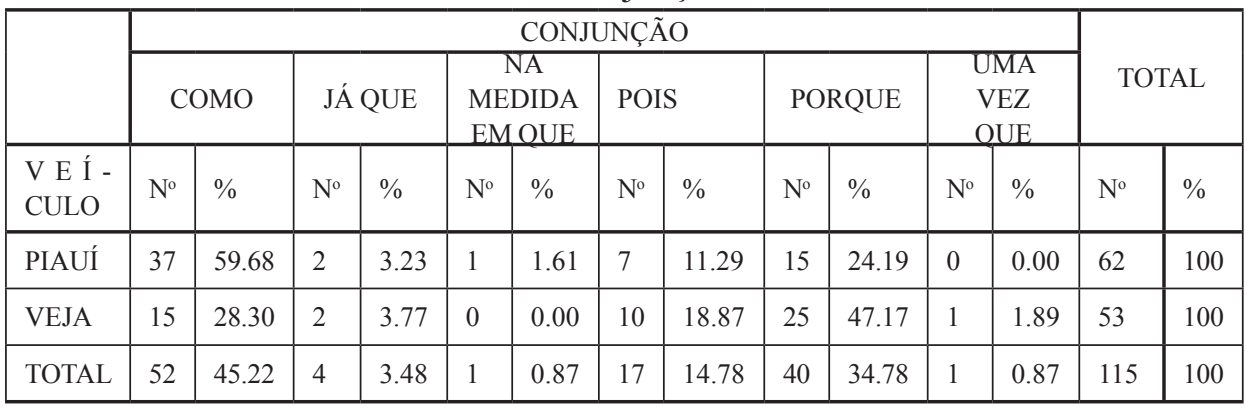

${ }^{5}$ Minitab 16 é uma ferramenta desenvolvida para a realização de cálculos estatísticos e análises de dados. 
Verifica-se nesse quadro uma diferença significativa entre os veículos examinados com respeito à ocorrência de como e porque. A conjunção como corresponde a 59,68\% dos dados da revista Piauí e a $28,30 \%$ dos dados da revista Veja, enquanto a conjunção porque corresponde a 24,19\% dos dados da revista Piauí e a 47,17\% dos dados da revista Veja. Há, portanto, uma inversão em relação à preferência por uma dessas conjunções. Todavia - e isto é o mais relevante para os propósitos deste estudo -, como e porque, junto com pois, têm uma ocorrência significativa nos dois veículos, figurando entre as conjunções mais frequentes. Do total de 115 conjunções que constituem os dados da investigação, como, porque e pois correspondem, respectivamente, a 45,22\% (52 dados), 34,78\% (40 dados) e 14,78\% (17 dados). Observase a ocorrência de apenas quatro conjunções já que, uma na medida em que e uma uma vez que.

As três conjunções mais frequentes implicaram combinações diferentes dos valores das variáveis examinadas, permitindo estabelecer quatro padrões de construção: 1) conjunção como, oração 2 anteposta, presença de vírgula, oração 2 como informação dada, oração 1 participando da continuidade tópica; 2) conjunção porque, oração 2 posposta, ausência de vírgula, oração 1 como informação dada, oração 2 participando da continuidade tópica; 3 ) conjunção pois, oração posposta, presença de vírgula, oração 2 como informação dada, oração 1 participando da continuidade tópica; 4) conjunção pois, oração posposta, presença de vírgula, nenhuma oração como informação dada, oração 1 e oração 2 participando da continuidade tópica. Conforme se vê, os dois primeiros padrões estão em consonância com os resultados da pesquisa de Neves (1999), em que predominam as conjunções como e porque. Desse modo, há indicações de que o terceiro e o quarto padrões são uma especificidade da escrita. Examina-se a seguir cada um deles separadamente.

As construções com a conjunção como invariavelmente implicam anteposição da oração 2 (uma característica que lhes é intrínseca) e o emprego de vírgula. Quanto à variável informação dada, observa-se o seguinte: 
Tabela 2 - Relação entre a ocorrência de informação dada e as orações que constituem construções com conjunção como, conforme o veículo

\begin{tabular}{|c|c|c|c|c|c|c|c|c|}
\hline \multirow[b]{3}{*}{ VEÍCULO } & \multicolumn{6}{|c|}{ INFORMAÇÃO DADA } & \multirow{2}{*}{\multicolumn{2}{|c|}{ TOTAL }} \\
\hline & \multicolumn{2}{|c|}{ ORAÇÃO 1} & \multicolumn{2}{|c|}{ ORAÇÃO 2} & \multicolumn{2}{|c|}{$\begin{array}{l}\text { NENHUMA } \\
\text { ORAC } \tilde{O}\end{array}$} & & \\
\hline & $\mathrm{N}^{\circ}$ & $\%$ & $\mathrm{~N}^{\mathrm{o}}$ & $\%$ & $\mathrm{~N}^{\circ}$ & $\%$ & $\mathrm{~N}^{\circ}$ & $\%$ \\
\hline PIAUÍ & 0 & 0.00 & 7 & 18.92 & 30 & 81.08 & 37 & 100 \\
\hline VEJA & 0 & 0.00 & 1 & 6.67 & 14 & 93.33 & 15 & 100 \\
\hline TOTAL & 0 & 0.00 & 8 & 15.38 & 44 & 84.62 & & 100 \\
\hline
\end{tabular}

Chama a atenção nesse quadro a diferença entre a revista Piauí e a revista Veja quanto à ocorrência de orações que constituem informação dada: sete ocorrências no primeiro veículo, correspondendo a 18,92\% do seu total de construções com como, e uma única ocorrência na revista Veja, ou seja, $6,67 \%$ do total de construções com como desse veículo. Parece, assim, haver uma correlação entre a preferência por orações com como, caso da revista Piauí (confira-se a Tabela 1), e o maior emprego dessas orações como informação dada. Pode-se supor que essa diferença decorre das especificidades dos textos que integram as duas revistas. Todavia, além de as diferenças entre esses veículos merecerem um exame mais cuidadoso - o que excede o propósito deste estudo -, é necessário lembrar que se registraram somente as ocorrências de informação efetivamente dada, excluindo-se conteúdos pressupostos, óbvios, implicados, entre outros que também integram o universo dos conteúdos tratados como velhos, mas cuja verificação é mais incerta. Isso significa que o número real de orações com informação dada não é o que se registra na Tabela 2; esta mostra o número mínimo inquestionável. Relativiza-se, assim, o número baixo de orações que, nas construções com como, portam informação dada - apenas oito em um total de 52 construções, ou seja, um percentual de 15,38\%. Acrescente-se que esse número ganha relevância com a consideração de que ele diz respeito exclusivamente à oração 2 (a oração introduzida pela conjunção como), o que indica que a oração 1 não pode portar informação dada. Com efeito, os resultados registrados na Tabela 3, a seguir, mostram que a oração 1 caracteriza-se por expressar informação nova: 
Tabela 3 - Relação entre a progressão tópica e as orações que constituem construções com conjunção como, conforme o veículo

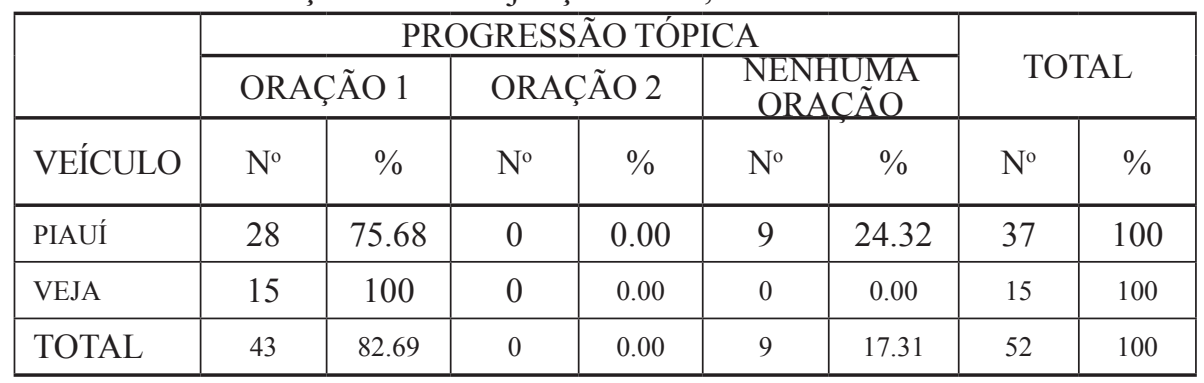

Observa-se aqui que, em 75,68\% das construções com como da revista Piauí, a oração 1 participa da continuidade tópica, evidenciando-se, assim, como aquela que porta a informação requerida. Com respeito às construções restantes, que constituem $24,32 \%$ do total de construções, não se pode dizer com certeza qual oração (se a 1 ou a 2) colabora com a continuidade tópica. Na revista Veja, por sua vez, a oração 1 é, em $100 \%$ dos casos, a oração em relação à qual a informação subsequente constitui um acréscimo. Do total dos dados das duas revistas, 82,69\% são de continuidade tópica estabelecida pela oração 1, não havendo um único dado de continuidade tópica estabelecida pela oração 2. Assim, os resultados da Tabela 3 mostram ser complementares aos da Tabela 2, em que a informação dada só pode ser expressa pela oração 2.

Veja-se um exemplo do padrão definido pelas construções com conjunção como:

(3) "Pela tomografia, era uma situação-limite, mas sem indicação clara para se recorrer à craniotomia descompressiva, ou tentar um procedimento menos agressivo", disse De Bellis. Como o quadro não era claro, ele sugeriu a Lobato e Vasconcelos a opção pela craniotomia. "Prefiro pecar pelo excesso", explicou.

No ano passado foram feitas 99 craniotomias de emergência no Miguel Couto (além de 44 eletivas), sendo 34 delas descompressivas, ou seja, com a retirada temporária de parte do crânio. [...] (Piauí, jul. 2010, p. 38, itálico nosso)

Nesse trecho de um artigo da revista Piauí, observa-se que a oração 2 ("como o quadro não era claro") traz uma informação já 
efetivamente dada na frase que a precede ("sem indicação clara para [...]"), enquanto a oração 1 ("ele sugeriu a Lobato e Vasconcelos a opção pela craniotomia") traz a informação nova, o conteúdo requerido, o que se verifica pelas informações subsequentes, todas relativas ao procedimento da craniotomia, e não mais à clareza do quadro de um paciente.

Por sua vez, as construções com porque, que definem o segundo padrão encontrado neste estudo, mostram-se menos regulares que as construções com como no que diz respeito à colocação da oração $2 \mathrm{e}$ ao emprego de vírgula. Quanto à colocação, trata-se de uma variação insignificante, visto que a posposição da oração 2 é quase categórica, tendo-se verificado apenas um dado de anteposição, o qual apresenta as mesmas características das construções com como. O emprego da vírgula é, contudo, mais variável, conforme se observa no quadro abaixo:

Tabela 4 - Presença de vírgula nas construções com conjunção porque, conforme o veículo

\begin{tabular}{|c|c|c|c|c|c|c|}
\hline \multirow{3}{*}{ VEÍCULO } & \multicolumn{4}{|c|}{ PRESENÇA DE VÍRGULA } & \multirow{2}{*}{\multicolumn{2}{|c|}{ TOTAL }} \\
\hline & \multicolumn{2}{|c|}{$\mathrm{NÃO}$} & \multicolumn{2}{|c|}{ SIM } & & \\
\hline & $\mathrm{N}^{\circ}$ & $\%$ & $\mathrm{~N}^{\circ}$ & $\%$ & $\mathrm{~N}^{\mathrm{o}}$ & $\%$ \\
\hline PIAUÍ & 14 & 93.33 & 1 & 6.67 & 15 & 100 \\
\hline VEJA & 19 & 76.00 & 6 & 24.00 & 25 & 100 \\
\hline TOTAL & 33 & 82.50 & 7 & 17.50 & 40 & 100 \\
\hline
\end{tabular}

A Tabela 4 mostra que as construções com porque admitem a presença e a ausência de vírgula e que a última opção é mais frequente na revista Veja. Todavia, a ausência de vírgula é suficientemente alta nos dois veículos que constituem o corpus deste trabalho para se reconhecer a existência de um padrão. Na revista Piauí ela corresponde a 93,33\% dos dados e na revista Veja a 76,00\%. Além disso, os dados com presença de vírgula se conformam aos padrões definidos pela conjunção pois, dos quais se tratará à frente. Assim, excluindo-se dos dados com porque os casos de anteposição da oração 2 e de presença de vírgula, verificaramse os resultados relativos à novidade da informação, que se mostraram opostos aos concernentes às construções com como. Veja-se, em primeiro lugar, o quadro dos valores da variável informação dada: 
Tabela 5 - Relação entre a informação dada e as orações que constituem construções com conjunção porque, conforme o veículo

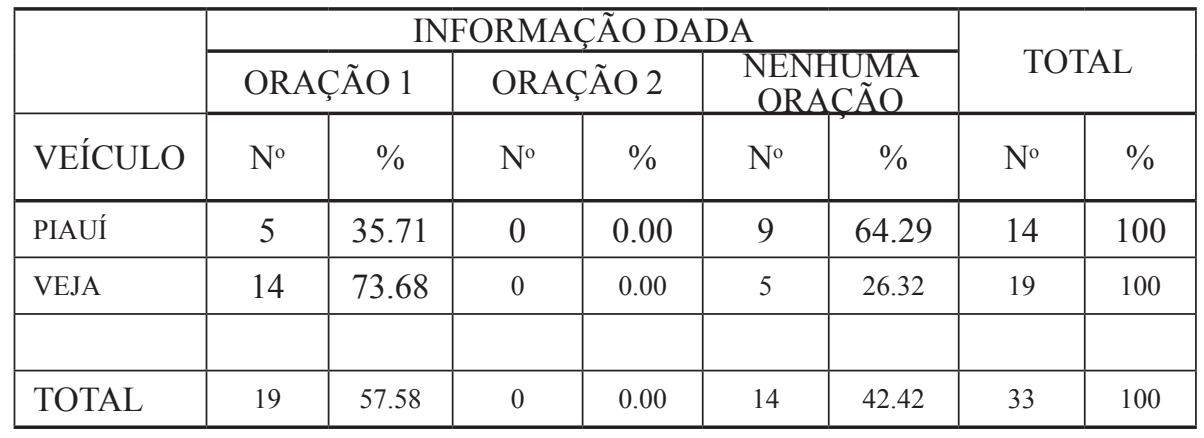

Mais uma vez, os números das revistas Piauí e Veja não são iguais, observando-se cinco ocorrências de informação efetivamente dada na primeira, correspondentes a 35,71\% dos seus dados com conjunção porque, e 14 ocorrências de informação efetivamente dada na última, correspondentes a $73,68 \%$ dos seus dados com porque. Entretanto, repete-se também o fato de nos dois veículos apenas uma oração ter potencial para portar a informação dada - nesse caso, a oração 1. Em relação complementar com esse fato, os resultados relativos à variável continuidade tópica são os seguintes:

Tabela 6 - Relação entre a progressão tópica e as orações que constituem construções com conjunção porque, conforme o veículo

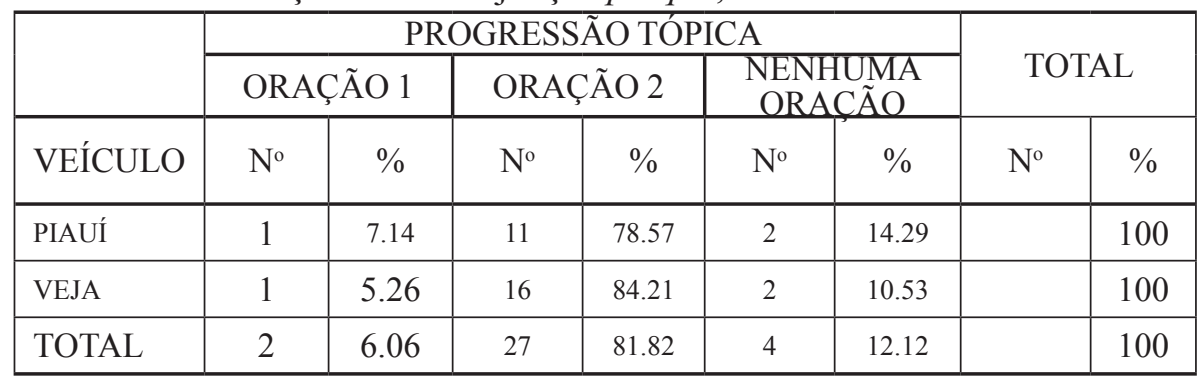

Embora haja duas ocorrências de oração 1 definindo a continuidade tópica (uma na revista Veja e outra na revista Piaui), verifica-se um padrão segundo o qual nas construções com a conjunção 
porque a continuidade tópica é estabelecida pela oração 2. Os números são decisivos a esse respeito: na revista Piauí a informação requerida é expressa pela oração 2 em 78,57\% dos dados com porque; na revista Veja ela é expressa por $84,21 \%$ dos dados com porque.

Veja-se um exemplo de construção com a conjunção porque que se conforma ao padrão descrito:

(4) [...] a Igreja Católica, na Idade Média, passou a cobrar dos fiéis para redimir seus pecados. A venda de indulgências pelo papado só era possível porque uma pessoa não podia perdoar a outra. No máximo, podia abster-se de procurar vingança como uma forma de ganhar pontos para, posteriormente, conseguir a própria redenção junto a Deus. O islamismo segue o mesmo princípio. (Veja, 28 jul. 2010, p. 131, itálico nosso)

Parte da oração 1 (“a venda de indulgências pelo papado") constitui uma outra maneira de se dizer o que foi dito na frase anterior, "que a Igreja Católica, na Idade Média, passou a cobrar dos fiéis para redimir seus pecados". A expressão que a finaliza, "só era possível", confirma isso: trata-se de um fato já afirmado, de cuja realidade não se duvida. A oração 1 porta, assim, a informação dada. A informação requerida, nova, é expressa pela oração 2 , que se refere ao perdão. Veja-se que a frase subsequente desenvolve essa temática e não a das indulgências.

Finalmente, em relação aos padrões definidos pela conjunção pois, pode-se afirmar que existe uma estabilidade quanto à colocação da oração 2 e ao uso da vírgula. Constata-se sempre a posposição dessa oração, devida a uma impossibilidade estrutural de movimento que lhe é inerente, e à presença de vírgula. A variável informação dada não se mostra muito diferente: a não ser por uma única ocorrência em um total de 17 dados, as construções com pois não admitem informação efetivamente dada, seja expressa pela oração 1, seja expressa pela oração 2. Veja-se a única ocorrência de informação dada:

(5) O que a Receita Federal faz em relação a esses pacotes de dinheiro que políticos e funcionários do governo vivem enfiando nos bolsos e bolsas? A Polícia Federal e o Ministério Público, a esta altura, já poderiam ter montado uma cinemateca inteira com os vídeos que registram essas cenas. Nunca acontece nada de sério com os indivíduos flagrados metendo a mão na massa, é claro. Mas como 
fica a sua situação perante o Fisco? Ninguém pode negar que recebeu, pois há prova filmada de que todos receberam. $\mathrm{O}$ que colocam, então, em suas declarações de renda? Se não declaram nem indicam a fonte pagadora, estão praticando sonegação. Se declaram e pagam o imposto devido, a Receita poderia ser acusada de estar cometendo crime de receptação, por receber parte de bens roubados. Como é que fica? (Veja, 01 ago. 2012, p. 142, itálico nosso)

No exemplo (8), a informação veiculada pela oração 2 ("pois há prova filmada de que todos receberam") constitui uma repetição de informação fornecida em trecho que a precede: "já poderiam ter montado uma cinemateca inteira com os vídeos que registram essas cenas". Nesse caso, a oração 1 ("ninguém pode negar que recebeu") vai ser responsável pela continuidade tópica. Observe-se que a frase subsequente, "o que colocam, então, em suas declarações de renda?", constitui uma questão relativa à impossibilidade expressa pela oração 1 . Dessa perspectiva, a construção com pois é uma alternativa à construção com como. Diferentes com respeito à colocação da oração 2, elas são equivalentes nas demais características: presença de vírgula, oração 2 portando informação dada, oração 1 definindo a continuidade tópica. Embora tenha ocorrido apenas um dado de oração 2 portando informação efetivamente dada, outros dados sugerem essa equivalência. Considere-se a seguinte ocorrência, extraída da revista Piauí:

(6) TERÇA - FEIRA - Depois de uma semana embarcada, tomo coragem e vou a terra. Durante esses dois meses, a rotina muda pouco. Saímos de Manaus sempre às quintas, por volta das onze da manhã, chegamos a Coari na tarde seguinte, saímos de lá com o carregamento no sábado e voltamos para Manaus na madrugada de domingo, onde ficamos fundeados até quinta-feira. Em Coari, a tripulação prefere ficar a bordo, pois ali a estadia não dura mais que dezoito horas. Todos aproveitam para assistir novela ou futebol. (Piauí, jul. 2010, p. 20, itálico nosso)

Nessa passagem, a construção com pois é encabeçada pela expressão "em Coari", a qual funciona, assim, como tema, em consonância com a referência feita antes a essa cidade. Nesse caso, o emprego de como em vez do de pois implicaria a dificuldade estrutural 
de se realizar uma anteposição a mais à oração 1, "a tripulação prefere ficar a bordo". A oração com pois parece, assim, ser uma alternativa à anteposição. Ela ancora a afirmação da oração-núcleo, como o faria a oração com como, constituindo a informação dada ou tratada como tal. Desse modo, a oração-núcleo permanece sendo aquela cujo conteúdo é requisitado: a informação da frase subsequente, "todos aproveitam para assistir novela ou futebol", é uma decorrência da informação da oraçãonúcleo, "a tripulação prefere ficar a bordo". Esse tipo de alternativa é importante na escrita, em que as construções podem atingir uma complexidade muito grande.

Essa análise das construções com a conjunção pois não é, todavia, possível sempre, conforme mostra a tabela relativa à variável continuidade tópica:

Tabela 7 - Relação entre a progressão tópica e as orações que constituem construções com conjunção pois, conforme o veículo

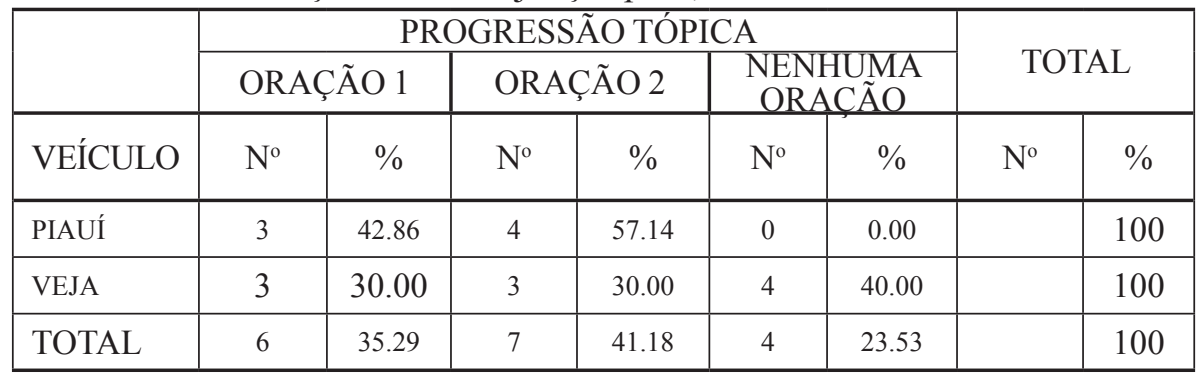

Independentemente do veículo, nas construções com pois a informação requerida pode estar situada na oração 1 ou na oração 2. A primeira possibilidade conduz, como se viu, à compreensão da construção com pois como uma alternativa à construção com com. A outra possibilidade exige uma compreensão diferente. Nesse caso, o que se verifica é que, apesar de apenas a oração 2 ter sido tomada como aquela que porta a informação requerida, essa é uma característica também da oração 1. Como o exame da variável continuidade tópica levou em conta apenas o futuro do texto a partir da construção focalizada, o que se mostrou suficiente no exame das demais construções que integram os dados deste estudo, a simultaneidade de orações expressando a informação pretendida não foi registrada na Tabela 7. Contudo, uma 
análise em separado das construções com pois em que a oração 2 é registrada como a pretendida mostra essa simultaneidade. Veja-se um exemplo:

(7) Dallas, porém, compensa os desserviços por seus préstimos ideológicos. Nos anos 80, teve sua pequena parte nos esforços de propaganda da Guerra Fria. Na Romênia, foi o único programa ocidental de exibição permitida, pois, na visão do ditador Nicolae Ceausescu, ilustrava a decadência do capitalismo. Ao verem Dallas, porém, os romenos se revoltavam ao constatar que, no padrão de vida americano, qualquer mortal tinha seu carrão. $\mathrm{O}$ programa também teve impacto na vida americana. Ao enaltecer o homem do interior e seu espírito empreendedor, contribuiu para a reinvenção política e econômica do país na era Reagan. Há que tirar o chapéu para um cabra tinhoso como J.R. (Veja, 27 jun. 2010, p. 147, itálico nosso)

Nessa construção, a informação expressa pela oração 1 ("na Romênia foi o único programa ocidental de exibição permitida") constitui um avanço em relação à informação que a precede ("nos anos 80 , teve sua pequena parte nos esforços de propaganda da Guerra Fria"), enquanto a oração 2 ("pois, na visão do ditador Nicolae Ceausescu, ilustrava a decadência do capitalismo") tanto avança em relação à oração 1 como constitui base para a introdução da novidade expressa pelo segmento que a sucede ("ao verem Dallas, porém, os romenos se revoltavam ao constatar que, no padrão de vida americano, qualquer mortal tinha seu carrão"). Observe-se que a informação desse segmento se opõe à informação da oração 2 por meio do operador textual porém.

Esse tipo de construção, diferente dos demais pelo fato de a informação requerida poder ser portada pelas orações 1 e 2 , reconduz à possibilidade de opor coordenação e subordinação, embora em novos termos. Da perspectiva que Neves (1999) denomina pragmática ou que, em Halliday (2004), refere-se ao âmbito da metafunção textual, a subordinação pode ser compreendida como um processo que vincula informações com níveis diferentes de relevância textual, enquanto a coordenação implica a igualdade, o paralelismo com respeito à novidade do conteúdo e, desse modo, à participação na continuidade tópica do texto. De acordo com essa compreensão, a subordinação é a relação que une 
as orações que compõem as construções com como, as construções com porque e parte das construções com pois, ao passo que a coordenação é a relação que caracteriza uma outra parte das construções com pois, aquela em que ambas as orações participam da continuidade tópica do texto.

Devem-se ainda considerar as conjunções que não são definidoras de padrões, mas também ocorreram no corpus examinado: já que, uma vez que e na medida em que. Elas se caracterizam igualmente por ocorreram em oração posposta e precedidas de vírgula, constituindo uma alternativa ao uso de pois nos dois padrões definidos por esta conjunção.

\section{Conclusão}

O estudo que aqui se relatou assumiu como propósito compreender o emprego da vírgula com as orações do português brasileiro tradicionalmente denominadas coordenadas explicativas e subordinadas adverbiais causais. Na impossibilidade de diferenciar efetivamente essas construções segundo os critérios tradicionais, recorreu-se a caracterização proposta por Neves (1999), assumindo-se um ponto de vista que ela chama de pragmático. Ignoraram-se, desse modo, as diferenças sintáticas e semânticas postuladas pela tradição, passando-se a observar o tipo de informação que essas orações expressam (se dada ou nova) e, conjugada a esse tipo, a sua contribuição para a continuidade tópica do texto em que se inserem.

Examinaram-se 115 dados de construções explicativas e causais extraídos de dois veículos de grande circulação no país (as revistas Piauí e Veja), operando-se com as seguintes variáveis: emprego da vírgula ( $\mathrm{sim} /$ não); conjunção (com/porqueljá que, entre outras); posição da oração 2 (anteposta/posposta à oração 1); informação dada (expressa pela oração 1/pela oração 2/por nenhuma das duas); continuidade tópica (baseada na oração 1/na oração 2/em nenhuma das duas). Encontraram-se quatro padrões de construção: 1) conjunção como, oração 2 anteposta, presença de vírgula, oração 2 como informação dada, oração 1 participando da continuidade tópica; 2) conjunção porque, oração 2 posposta, ausência de vírgula, oração 1 como informação dada, oração 2 participando da continuidade tópica; 3) conjunção pois, oração posposta, presença de vírgula, oração 2 como informação dada, oração 1 participando da continuidade tópica; 4) conjunção pois, oração posposta, presença de vírgula, nenhuma oração como informação dada, oração 1 e oração 2 participando da continuidade tópica. 
Esses resultados implicaram ainda as seguintes conclusões: os padrões definidos pela conjunção pois devem ser uma exclusividade da escrita, visto que não correspondem aos resultados encontrados em Neves (1999), referentes ao português falado culto; embora os padrões sejam definidos por uma única conjunção, considerando-se a sua ocorrência predominante, pode haver variação, a qual é mais significativa em relação à conjunção pois; do ponto de vista pragmático proposto por Neves (1999), a subordinação pode ser compreendida como um processo que vincula informações com níveis diferentes de relevância textual, ao passo que a coordenação implica o paralelismo com respeito à novidade do conteúdo, de modo que se podem identificar com a coordenação apenas os dados do padrão definido pela conjunção pois no qual as orações 1 e 2 portam informação requerida; embora se tenham reconhecido padrões de construção válidos para as duas revistas examinadas, esses padrões não se cumpriram nelas de modo uniforme, o que indica diferenças entre instâncias discursivas.

Por fim, atendendo-se à finalidade do estudo proposto, sintetizamse as condições de emprego da vírgula nas construções examinadas: usa-se a vírgula para separar da oração-núcleo a oração introduzida por conjunção quando esta última porta informação dada (informação não requerida) ou quando esta última é paralela à primeira, ambas portando informação nova (informação requerida, que contribui para a continuidade tópica do texto).

\section{Referências}

CEGALLA, D. P. Novíssima gramática da língua portuguesa. 45. ed. São Paulo: Companhia Editora Nacional, 2002.

HALLIDAY, M. A. K. An introduction to functional grammar. 3. ed. Londres: Hodder Education, 2004.

NEVES, M. H. de M. As construções causais. In: (Org.), Gramática do português falado: São Paulo/Campinas: Humanitas/FFLCH/USP/Ed. da Unicamp, 1999. Vol. VII (Novos Estudos), p. 461-496,

ROCHA LIMA, C. H. da. Gramática normativa da língua portuguesa. 37. ed. Rio de Janeiro: José Olympio, 1999. 